$16^{\text {th }}$ International Conference on

AEROSPACE SCIENCES \& AVIATION TECHNOLOGY,

ASAT - 16 - May 26 - 28, 2015, E-Mail: asat@ mtc.edu.eg

Military Technical College, Kobry Elkobbah, Cairo, Egypt

Tel : +(202) 24025292 - 24036138, Fax: +(202) 22621908

\title{
Surface Composite Preparation by Friction Stir Processing
}

\author{
Fahima Ragab* ${ }^{*}$, Abdelkarim Ahmed ${ }^{\dagger}$, Ramadan Seoudy $^{\ddagger}$, Ahmed El-Nikhaily $^{\S}$
}

\begin{abstract}
Grooves of $1 \mathrm{~mm}$ depth and of different widths 1, 1.5, or $2 \mathrm{~mm}$ are made on the surface of AA5083 Al alloy plates and filled with 1.07:112.35 $\mu \mathrm{m}$ alumina powder. Then, the surface is treated with friction stir processing "FSP" to form a composite surface layer of AA5083 matrix reinforced with alumina particles. FSP is carried out using a tool rotational speed of $1400 \mathrm{rpm}$, processing speed of $25 \mathrm{~mm} / \mathrm{min}$ and a plunge depth of $4.3 \mathrm{~mm}$. Prepared surface composites are subjected to microstructure investigation, Vickers hardness measurements, and wear rate determination. For comparison, as-received and FSP 5083 Al alloy are subjected, also, to similar tests. The composite layer thickness decreases from 0.8 to 0.7 and to $0.6 \mathrm{~mm}$ at $1,1.5$, and $2 \mathrm{~mm}$ groove widths, respectively. It seems that, the stirring conditions i.e. $1400 \mathrm{rpm}$ rotation speed, $25 \mathrm{~mm} / \mathrm{min}$ travel speed and $4.3 \mathrm{~mm}$ plunge depth are not suitable to specimens with alumina grooves wider than $1 \mathrm{~mm}$, where the alumina powder is expelled out of the stir zone, as indicated by micro-structural observations. The surface micro-structure of $1 \mathrm{~mm}$ alumina groove specimens shows highest alumina volume fraction.

Such specimens possess highest surface micro-hardness numbers of about 120, while those with wider grooves possessed values of only about 100. Moreover, FSP of the surface layer increases the wear resistance of present alloy, especially at higher sliding velocities. However, the wear resistance is dramatically raised when alumina powder is added to form surface composite.
\end{abstract}

Keywords: Friction stir processing (FSP), Surface composite (SC), A5083 alloy

\section{1-INTRODUCTION}

Aluminum alloys are very promising for structural applications in aerospace, military and transportation industries, due to their light weight, high strength-to-weight ratio, and excellent resistance to corrosion. However, low hardness and low strength of aluminium alloys limit their use, especially for tribological applications [1].

Friction stir processing (FSP) is an emerging novel processing technique as a surface treatment, or to fabricate surface composites which is based on the basic principles of friction stir welding (FSW). Some advantages of FSP are micro-structural refinement, densification, homogeneity, accurate control and variable depth of the processed zone. FSP is a green and energy efficient technique without deleterious gases and does not change the shape and size of the processed component [2]

\footnotetext{
M.Sc. student, Faculty of Industrial Education, Suez University, Egypt.

$\dagger$ Lecturer, Faculty of Industrial Education, Suez University, Egypt.

$\$$ Professor, Faculty of Engineering, Suez Canal University, Egypt. dr_ramadan2011@yahoo.com

$\S$ Professor, Faculty of Industrial Education, Suez University, Egypt.
} 
Friction stir processing (FSP) can be an important enabling technology for the construction of aluminum and magnesium lightweight vehicle substructures. FSP is a means to modify properties of castings. It can dramatically refine grain structures, and improve a variety of properties, that are crucial in vehicle structural applications. Friction stir processing also can be used to modify microstructures to improve the surface properties of metals, a capability that is of particular interest for transportation applications.

Some researchers [2-8] observed that, the addition of particle material to some aluminum alloys improves the mechanical properties and resistance to wear.

N. Murugan et al [2] in 2012 studied the microstructure and micro-hardness of AA1050/TiC surface composite, fabricated using friction stir processing. The microstructure and micro-hardness of the fabricated AMC were analyzed. Scanning Electron Microscope (SEM) micrographs revealed a uniform distribution of TiC particles, which were well-bonded to the matrix alloy. The hardness of AMC was $45 \%$ higher than that of the matrix alloy.

Mingzhao [3] in 2001 studied the effect of the addition of alumina and silicon carbide on the mechanical properties of aluminum alloy Al-2618, and the effect of thermal treatment on such properties. Mingzhao [3] noted that, the effect of adding silicon carbide particles on tensile strength and hardness is bigger than that of adding aluminum oxide.

Keesam Shin and Sunghak Lee [4] in 2003 studied property improvement of stainlesssteel-base surface composites fabricated by high-energy electron-beam irradiation. Powders and substrate surface were melted and surface composite layers were successfully formed. In specimens fabricated with $\mathrm{SiC}$ powders, a volume fraction of $\mathrm{Cr}_{23} \mathrm{C}_{6}$ particles ( 22 vol.\%) were homogeneously distributed along the solidification cell boundaries. The large amount of $\mathrm{Cr}_{23} \mathrm{C}_{6}$ particles in combination with solid solution hardening of $\mathrm{Si}$ in the matrix strongly improved hardness and wear resistance of the surface composite layer. On the other hand, in specimens fabricated with $\mathrm{SiC}$ and $\mathrm{Ti}+\mathrm{SiC}$ powders, only $\mathrm{TiC}$ and $\mathrm{Cr}_{23} \mathrm{C}_{6}$ particles were precipitated without precipitation of SiC. Sinha [5] in 2006 studied the effect of adding (NiTi) on the mechanical properties of pure aluminum. The results showed an increase in tensile strength and hardness compared to base metal.

Y. Morisada [6] et al in 2007 studied fullerene/A5083 composites fabricated by friction stir processing. The obtained results can be summarized as follows: First, fullerene molecules can be dispersed in A5083 matrix using FSP. $\square$ Second, onion ring is formed by the convectional flow due to the shoulder. Third, FSP with fullerene obviously increases the microhardness of the substrates by the promotion of grain refinement, due to the pinning 
effect of fullerene and its extremely high hardness. Fourth, A5083 with a grain size of less than $200 \mathrm{~nm}$ is easily obtained using fullerene dispersion.

Seder [7] in 2008 studied the effect of particle size of SiC added to pure aluminum. Silicon carbide particle sizes of 125, 250, 500 microns were used applying powder metallurgy technique. It was found that, the use of 125 microns particulate size gave the highest hardness and wear resistance values.

Essam R. I. Mahmoud [8] et al in 2009 studied the fabrication of surface-hybrid-MMCs layer on aluminum plate by friction stir processing and its wear characteristics. It was found that, the reinforcement particles were distributed homogenously inside the nugget zone without defects, except some voids that appeared around the $\mathrm{Al}_{2} \mathrm{O}_{3}$ particles. The average hardness decreased with increasing the relative content of $\mathrm{Al}_{2} \mathrm{O}_{3}$ particles. Regarding wear characteristics, the wear volume losses of the hybrid composites depended on the applied load and the relative ratio of $\mathrm{SiC}$ and $\mathrm{Al}_{2} \mathrm{O}_{3}$ particles. The hybrid composite of $80 \% \mathrm{SiC}+20 \%$ $\mathrm{Al}_{2} \mathrm{O}_{3}$ showed superior wear resistance to $100 \% \mathrm{SiC}$ and $\mathrm{Al}_{2} \mathrm{O}_{3}$ or any other hybrid ratio, under a normal load of $5 \mathrm{~N}$.

The objective of the current research is to study the effect of the addition of alumina particles on the hardness and dry wear resistanes of (A5083) alloy.

\section{EXPERIMENTAL PROCEDURE}

Friction stir processing of plates $300 \times 200 \times 10 \mathrm{~mm}$ of $5083 \mathrm{Al}$ alloy is studied. The alloy contains 4.0-4.9\% Mg and 0.4-1.0\% Mn. The surface of the $5083 \mathrm{Al}$ alloy plate is doped through FSP with alumina powder 1.07:112.35 $\mu \mathrm{m}$, as indicated in Fig.1, to produce surface composite. The set up used for carrying out FSP consists of a vertical milling machine and a specially designed FSP tool. The fixture for holding the base plate during FSP was designed and fabricated, Fig. 2.

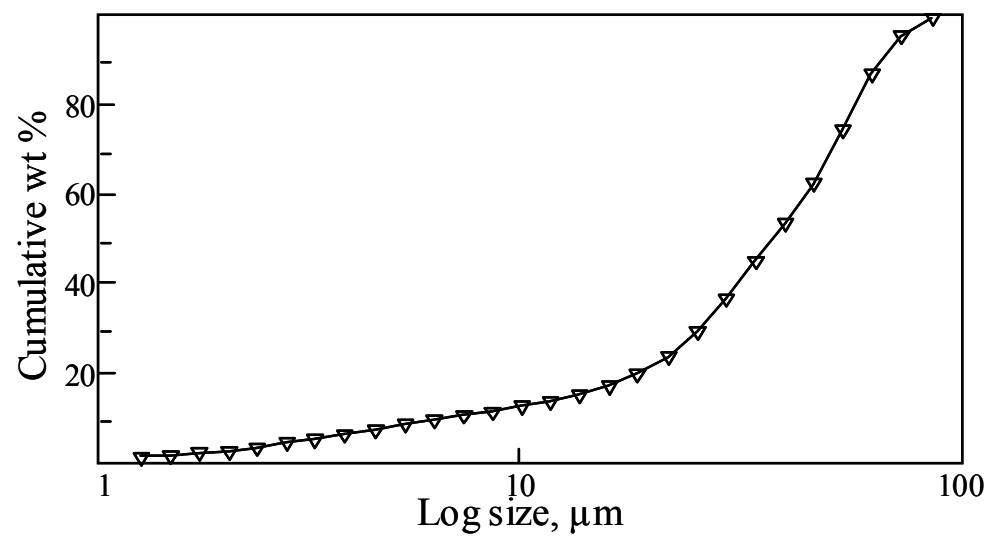

Fig.1 Particle size distribution of alumina powder. 


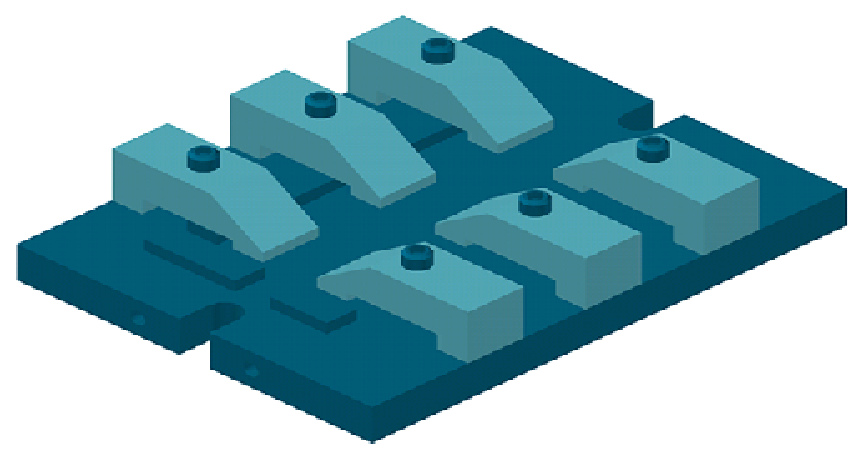

Fig. 2 Fixture for holding specimens during FSP

A specially designed friction stir processing tool, Fig.3, with a shoulder and pin is used. The tool is made of high strength steel of around 61-62 HRC hardness.
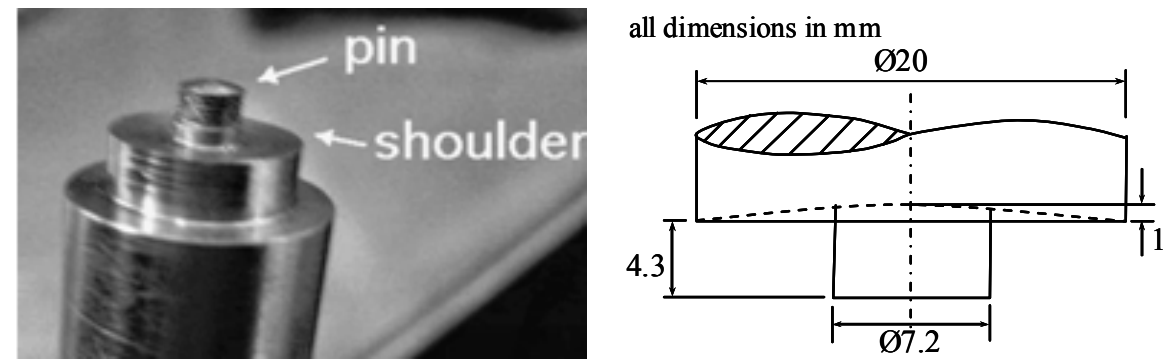

Fig.3 Friction stir processing tool

The fixture containing a duly gripped base plate is placed and tightened to the bed of a vertical milling machine. Grooves, $1 \mathrm{~mm}$ deep, are then made on the surface of samples with different widths of $1,1.5$, and $2 \mathrm{~mm}$, and the grooves are filled with alumina powder. Thereafter, the FSP tool is mounted in the spindle of milling machine, and the spindle rotates at $1400 \mathrm{rpm}$, and the machine bed is moved at a speed of $25 \mathrm{~mm} / \mathrm{min}$. The FSP tool is plunged into the base plate, to a depth of $4.3 \mathrm{~mm}$. As the rotating tool moves along the grooves centre line, a layer of $5083 \mathrm{Al}-\mathrm{Al}_{2} \mathrm{O}_{3}$ composite is produced on the surface of base plate, Fig. 4 and Fig. 5.

(a)

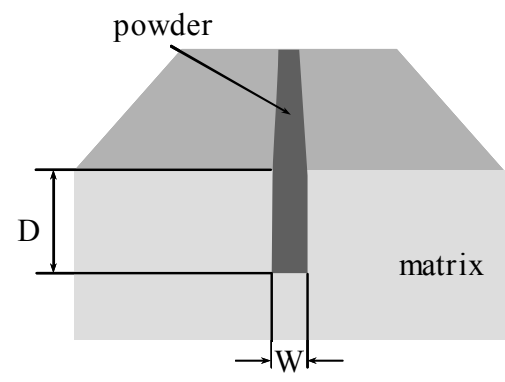

(b)

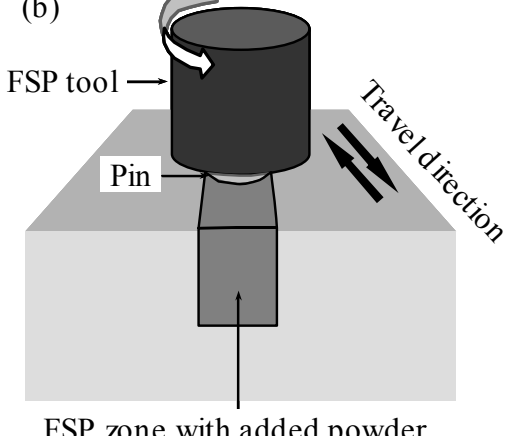

Fig.4 Schematics of FSP, groove depth D is $1 \mathrm{~mm}$ and its width $\mathrm{W}$ is $1,1.5$, or $2 \mathrm{~mm}$. 

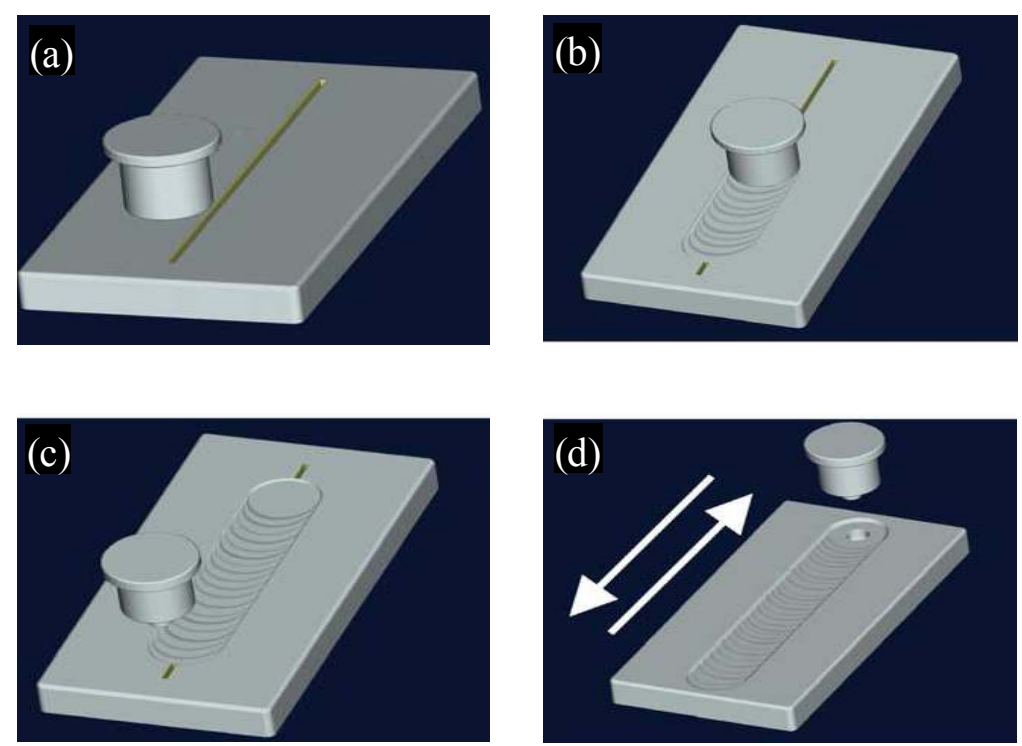

Fig.5 Surface composite preparation procedure. (a) Cutting grooves and inserting powder,

(b) Use of a flat tool for surface repair; (c) Use of a tool with a fixed pin for FSP; and (d) Applying multiple FSP passes [9].

\subsection{Microstructure Investigation}

Samples of prepared AA5083 reinforced with alumina particles are prepared for microstructure investigation. The samples are grinded, successively, with emery papers 180, 320, 500, 1000, then 1200 mesh using Metkon-Gripo2v grinding machine. Microstructure is revealed using Keller's reagent.

\subsection{Micro-hardness Testing}

Micro-hardness of friction stir processed samples is measured at various locations, from the processed zone to base metal. Before performing the test, the specimen is well polished. The micro-hardness number is then calculated by Matsuzawa Modul DMH'2 device. Each micro-hardness value is the average of at least three readings using 100 gm load.

\subsection{Wear Test}

The wear rate of friction stir processed test specimens, and of un-processed ones is evaluated on a pin-on-disk type wear testing machine. Flat specimens $8 \times 8 \mathrm{~mm}$ in cross section and $10 \mathrm{~mm}$ long are cut from the nugget zone of the FSP sample, as well as from the base alloy plate. Such flat specimens fit tightly into a $30 \mathrm{~mm}$ long pin shaped holder with 10 $\mathrm{mm}$ diameter. The holder is provided with a circular slot to adjust the cut specimen. The pin holding the flat specimen is tightened in the grips provided with the wear testing machine, which is secured inside the loading arm, carrying a normal load of $8.8 \mathrm{~N}$. The sample is held 
against a rotating disc made of EN32 steel $(\mathrm{HRC}=62)$ at a constant sliding speed of 1,3 , or 5 $\mathrm{m} / \mathrm{min}$, and the test duration is $15 \mathrm{~min}$. The weight loss of the sample is measured using an electron weighing balance of accuracy $0.001 \mathrm{mg}$. Wear rate is calculated from the following equation:

$$
\text { Wear rate }=\Delta \mathrm{W} / \mathrm{S} \quad(\mathrm{gm} / \mathrm{cm})
$$

Where, $\Delta \mathrm{W}$ is the weight loss in gm, $\Delta \mathrm{W}=\mathrm{W}_{1}-\mathrm{W}_{2}$ gm,

$\mathrm{W}_{1}$ is the weight after test, and $\mathrm{W}_{2}$ is the weight before test gm,

$\mathrm{S}$ is the sliding distance $=2 \pi \mathrm{rnt} \mathrm{cm}$,

$\mathrm{n}$ is the rotation speed rpm,

$\mathrm{t}$ is the time $=8.8 \mathrm{~min}$.

Table 1 Wear test conditions

\begin{tabular}{|c|c|c|c|}
\hline \multirow{2}{*}{$\begin{array}{c}\text { Experiment } \\
\text { No. }\end{array}$} & \multicolumn{3}{|c|}{ Test Conditions } \\
\cline { 2 - 4 } & Speed, m/min & Time, min & Load, N \\
\hline 1 & 5 & 15 & 8.8 \\
\hline 2 & 3 & 15 & 8.8 \\
\hline 3 & 1 & 15 & 8.8 \\
\hline
\end{tabular}

\section{RESULTS AND DISCUSSION}

In order to investigate the effect of doping $\mathrm{Al}_{2} \mathrm{O}_{3}$ particles on $5083 \mathrm{Al}$ plate through $\mathrm{FSP}$, the specimens are characterized for microhardness and wear test. The results obtained for friction stir processed samples are compared with those obtained for unprocessed $5083 \mathrm{Al}$ alloy.

Table 2 Test specimen designation

\begin{tabular}{|c|l|}
\hline Designation & \multicolumn{1}{|c|}{ Description of specimen conditions } \\
\hline S00 & Base alloy without FSP and no alumina addition \\
\hline S0 & Base alloy with FSP but no alumina addition \\
\hline S1 & Surface composite groove is $1 \mathrm{~mm}$ deep and $1 \mathrm{~mm}$ wide \\
\hline S2 & Surface composite groove is $1 \mathrm{~mm}$ deep, and $1.5 \mathrm{~mm}$ wide \\
\hline S3 & Surface composite groove is $1 \mathrm{~mm}$ deep, and $2 \mathrm{~mm}$ wide \\
\hline
\end{tabular}

\subsection{Microstructure}

Figure 6 shows a cross section of three surface composite samples. It is observed that, the surface composite layer thickness is about $0.08 \mathrm{~mm}$ in the case of $1 \mathrm{~mm}$ groove width, whereas the thickness decreases to 0.06 in the case of $2 \mathrm{~mm}$ groove width. It seems that, the 
stirring conditions i.e. $1400 \mathrm{rpm}$ rotation speed, and $25 \mathrm{~mm} / \mathrm{min}$ travel speed, and 4.3 plunge depth are not suitable to higher $\mathrm{Al}_{2} \mathrm{O}_{3}$ contents, i.e. wider alumina grooves. The alumina powder in the case of groove widths greater than $1 \mathrm{~mm}$ may be expelled out the stir zone.
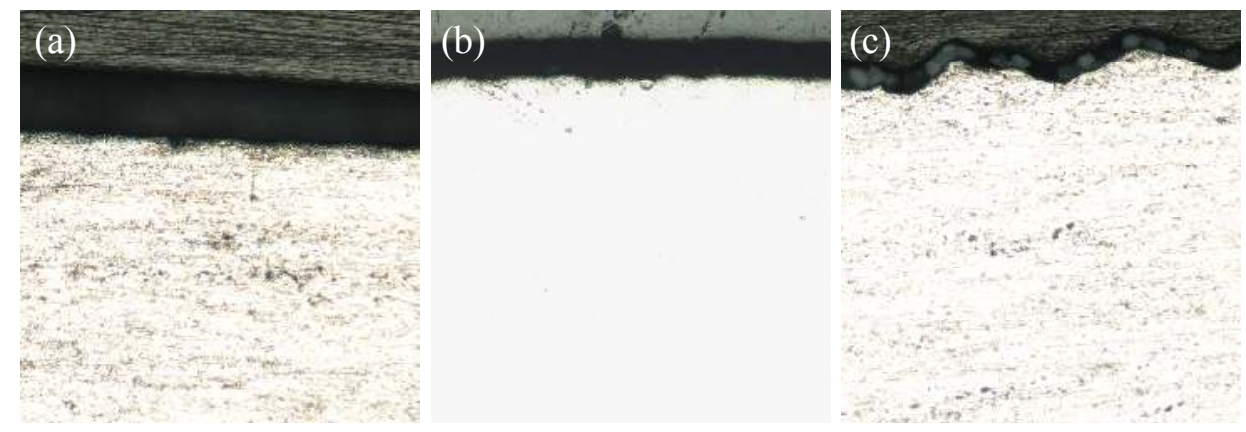

Fig.6 Cross sections of three different surface composites. (a) Groove width $1 \mathrm{~mm}$, composite layer $=0.8 \mathrm{~mm}$. (b) Groove width $1.5 \mathrm{~mm}$, composite layer $=0.7 \mathrm{~mm}$. (c) Groove width $2 \mathrm{~mm}$, composite layer $=0.6 \mathrm{~mm}$.

Figure 7 shows the microstructure on the surface of different surface composites. It is obvious that the alumina volume fraction of the specimen with $1 \mathrm{~mm}$ groove width, Fig. $7 \mathrm{a}$ is the largest realized volume fraction. This agrees with previous observation that, the stirring conditions are not suitable to higher $\mathrm{Al}_{2} \mathrm{O}_{3}$ contents, i.e. wider $\mathrm{Al}_{2} \mathrm{O}_{3}$ grooves. For specimens with grooves wider than $1 \mathrm{~mm}$, alumina powder is expelled out stir zone.
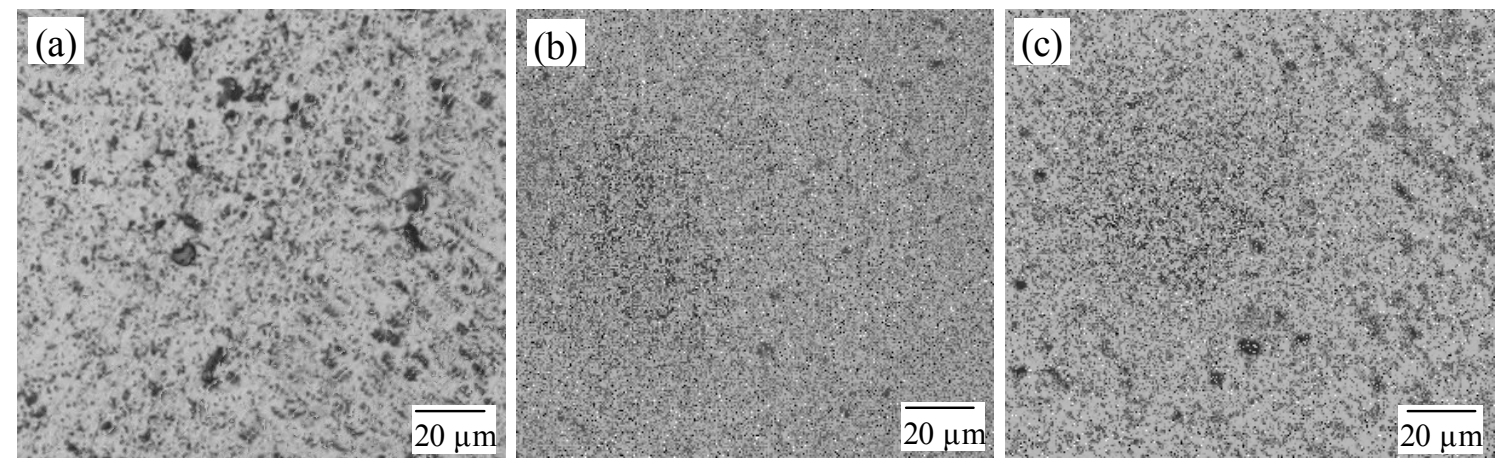

Fig.7 Microstructure of surface composites for specimens with: (a) one mm groove width,

(b) $1.5 \mathrm{~mm}$ groove width and (c) $2 \mathrm{~mm}$ groove width.

\subsection{Micro-hardness Measurements}

Micro-hardness is measured on the cross-section of test specimens to determine the depth of the composite layer, and the strengthening of the surface layer. Micro-hardness distribution of the subsurface layer of is determined as indicated in Fig.8. Measured values as averages of at least three identical indentations are then plotted against the depth from the surface, as shown in Fig.9. It is generally observed that, the hardness decreases with increasing depth beneath the surface. The depth of the surface layer is about $0.7 \mathrm{~mm}$. The 
micro-hardness of composites at a depth of $0.7 \mathrm{~mm}$ is about 85 . However, the surface microhardness of specimens with $2 \mathrm{~mm}$ groove and those with $1.5 \mathrm{~mm}$ groove width is about 100 , while that of $1 \mathrm{~mm}$ groove width reaches a micro-hardness number of 120 .

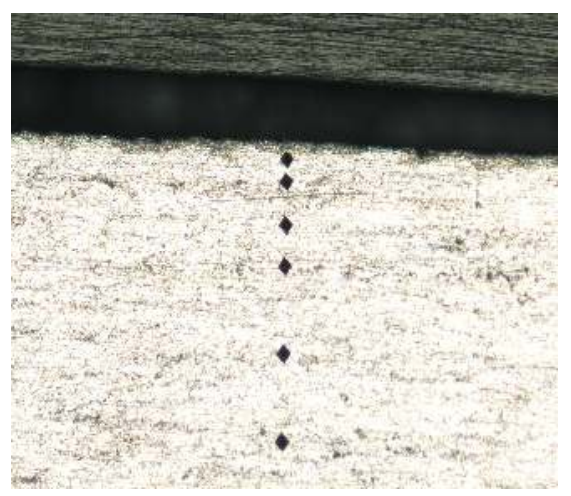

Fig.8 Micro-hardness indentations on SC sample cross-section

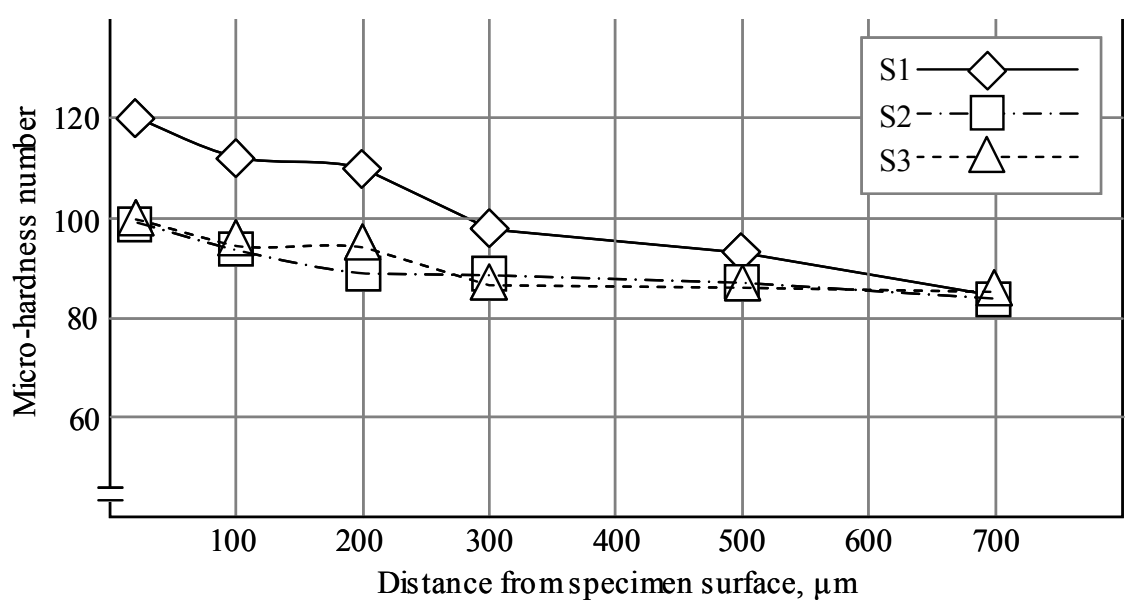

Fig.9 Micro-hardness distribution through the cross section of the SC samples (zero distance stands for the micro-hardness on the surface).

\subsection{Wear Rate Determination}

The rate of wear is experimentally determined for surface composite specimens S1, S2, S3 containing different contents of alumina. For comparison, the wear rates of as received $5083 \mathrm{Al}$ alloy "S00", and FSP $5083 \mathrm{Al}$ alloy "S0" are also determined. To study the effect of sliding speed, three speeds $5,3,1 \mathrm{~m} / \mathrm{min}$ are applied. The obtained results are plotted in Fig. 10 ( $5 \mathrm{~m} / \mathrm{min}$ speed), Fig.11 ( $3 \mathrm{~m} / \mathrm{min}$ speed), and Fig.12 (1 m/min speed). 


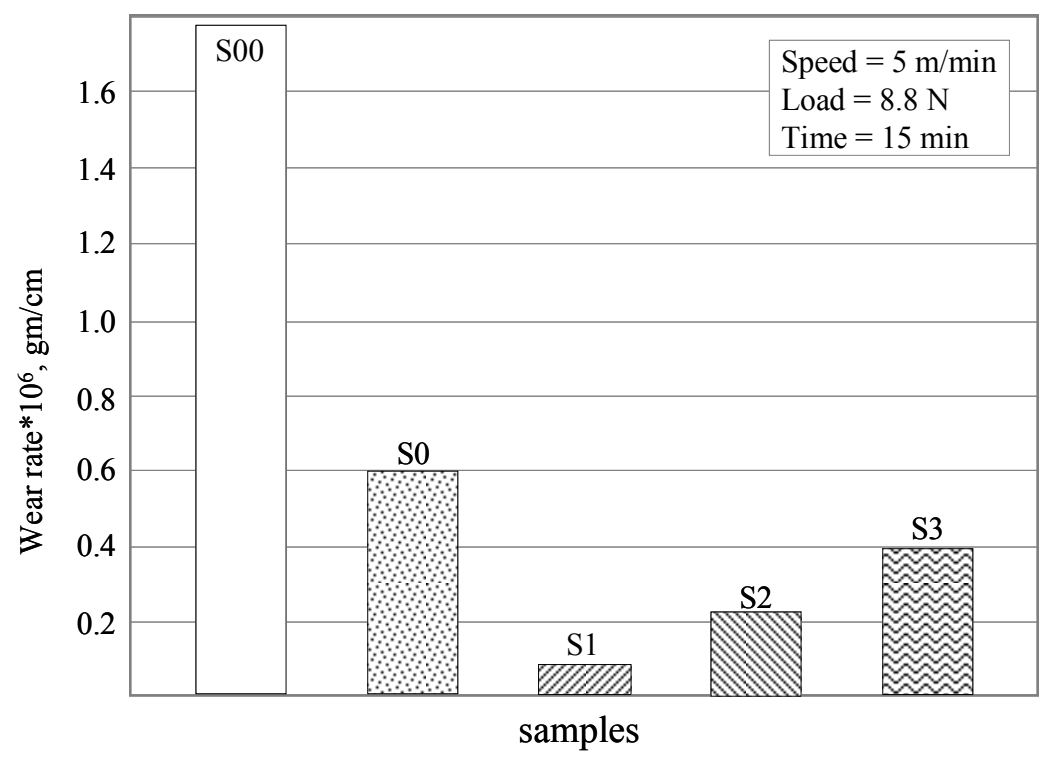

Fig.10 Wear rate of surface composite specimens (S1, S2, S3), and base metal with and without stirring $(\mathrm{S} 0, \mathrm{~S} 00)$ at $5 \mathrm{~m} / \mathrm{min}$ speed.

It is obvious from Fig. 10 that, the wear rate of specimen S1, i.e. surface composite with one $\mathrm{mm}$ groove width is the lowest rate $\left(0.0887 \times 10^{-6} \mathrm{gm} / \mathrm{cm}\right)$. Specimen $\mathrm{S} 1$ has the highest micro-hardness on the surface, Fig.9. It is also observed that, FSP without the addition of alumina lowers the wear rate of the as-received alloy to one third of its value.

When the sliding speed is lowered to $3 \mathrm{~m} / \mathrm{min}$, some variation of the wear rate results takes place, as shown in Fig.11. It is obvious from Fig. 11 that, the wear rate of specimen S1, i.e. surface composite with $1 \mathrm{~mm}$ groove width is the lowest rate $\left(0.0689 \times 10^{-6} \mathrm{gm} / \mathrm{cm}\right)$

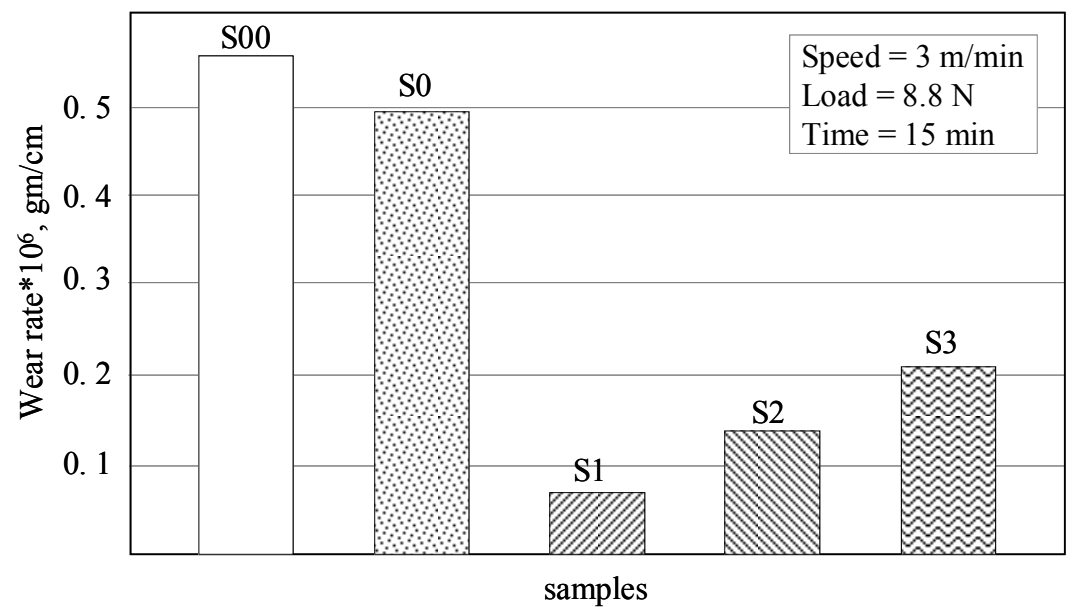

Fig.11 Wear rate of surface composite specimens (S1, S2, S3), and base metal with and without stirring ( $\mathrm{S} 0, \mathrm{~S} 00)$ at $3 \mathrm{~m} / \mathrm{min}$ speed.

It is obvious from Fig. 12 that, the wear rate of specimen S1, i.e. surface composite 
with $1 \mathrm{~mm}$ groove width is the lowest wear rate $\left(0.00033 \times 10^{-6} \mathrm{gm} / \mathrm{cm}\right)$, and lowest wear rate when compared with speed $3 \mathrm{~m} / \mathrm{min}$ and speed $1 \mathrm{~m} / \mathrm{min}$.

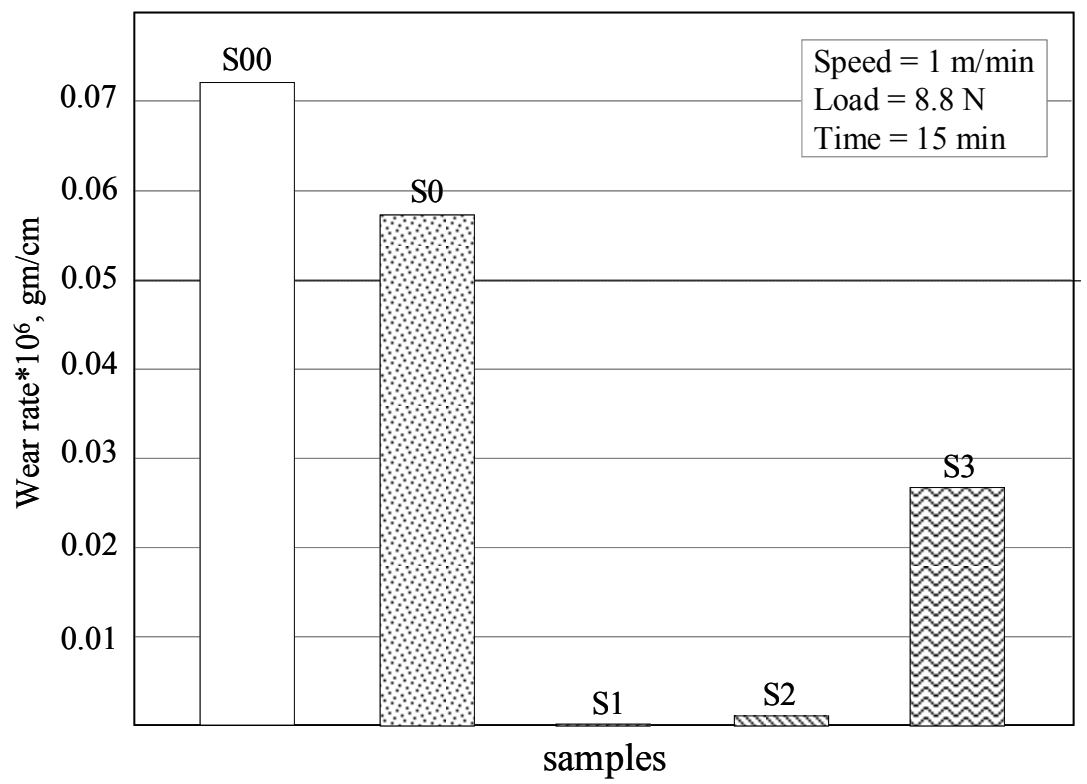

Fig.12 Wear rate of surface composite specimens (S1, S2, S3), and base metal with and without stirring $(\mathrm{S} 0, \mathrm{~S} 00)$ at $1 \mathrm{~m} / \mathrm{min}$ speed.

It is clear that, best wear resistance is achieved when the alumina groove width is $1 \mathrm{~mm}$. So, the variation of the wear resistance with speed is indicated in Fig. 13. the figure indicates that, the wear rate at a load of $8.8 \mathrm{~N}$ is strongly dependent on speed. At $1 \mathrm{~m} / \mathrm{min}$ the wear rate is $0.0033 * 10^{-6} \mathrm{gm} / \mathrm{cm}$. Increasing the speed to $3 \mathrm{~m} / \mathrm{min}$ increases the wear rate to $0.069 * 10^{-6}$. Further increase of the speed to $5 \mathrm{~m} / \mathrm{min}$ raises the wear rate to $0.089 * 10^{-6} \mathrm{gm} / \mathrm{cm}$.

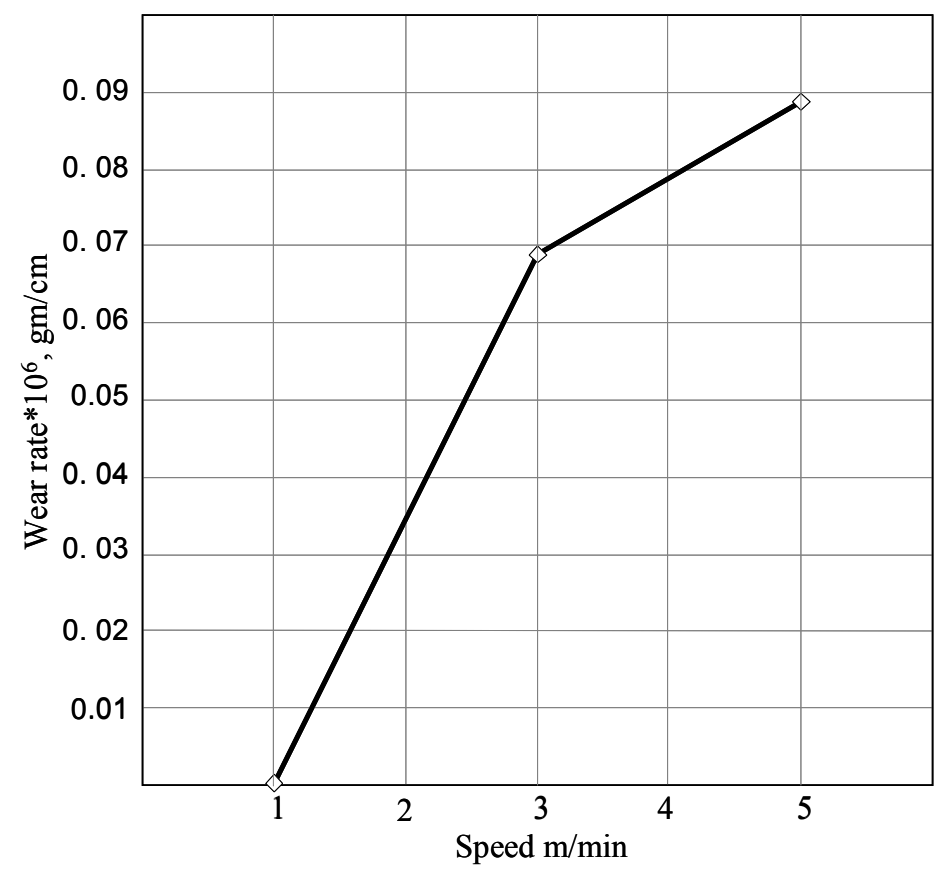

Fig.13 Wear rate of surface composite specimens (S1), at $1 \mathrm{~m} / \mathrm{min}$ speed. 


\section{CONCLUSIONS}

Based on present results the following could be concluded:

1) Grooves, $1 \mathrm{~mm}$ deep, are made on the surface of A5083 matrix specimens with different widths of $1,1.5$, and $2 \mathrm{~mm}$, and filled with alumina powder, then friction stir processing is applied to form surface layer composite.

2) Stirring conditions, $1400 \mathrm{rpm}$ rotation speed, $25 \mathrm{~mm} / \mathrm{min}$ travel speed and $4.3 \mathrm{~mm}$ plunge depth, are not suitable to specimens with alumina grooves wider than $1 \mathrm{~mm}$. In case of wide grooves, alumina powder is expelled out of the stir zone, as indicated by micro-structural observations, and supported by micro-hardness measurements.

3) Friction stir processing of $5083 \mathrm{Al}$ alloy significantly raises its wear resistance. However, the addition of alumina powder to form surface composite by FSP, dramatically raises its wear resistance.

4) The wear rate at $1 \mathrm{~m} / \mathrm{min}$ is $0.0033 * 10^{-6} \mathrm{gm} / \mathrm{cm}$. Increasing the speed to $3 \mathrm{~m} / \mathrm{min}$ increases the wear rate to $0.069 * 10^{-6}$. Further increase of the speed to $5 \mathrm{~m} / \mathrm{min}$ raises the wear rate to $0.089 * 10^{-6} \mathrm{gm} / \mathrm{cm}$.

\section{REFERENCES}

[1] Dharmpal Deepak1, Ripandeep Singh Sidhu1, V.K Gupta11 Department of Mechanical Engineering, UCoE, Punjabi University, Patiala.

[2] A. Thangarasu, N. Murugan, I. Dinaharan, and S. Jvijay, Microstructure and MicroHardness of AA1050/TiC Surface Composite, Fabricated Using Friction Stir Processing, Sadhana Vol. 37, Part 5, October 2012, pp. 579-586.

[3] Mingzhao, Journal of material science 36 (pp. 2045-2053) (2001).

[4] Keesam Shin and Sunghak Lee, Property Improvement of Stainless-Steel-Base Surface Composites Fabricated by High-Energy Electron-Beam Irradiation , METALS AND MATERIALS International, Vol. 9, No. 6 (2003), pp.

[5] Asinha IE (I) Journal MMVol.87, Abril (2006).

[6] Y. Morisada, H. Fujii, T. Nagaoka, K. Nogi. Morisada, H. Fujii, T. Nagaoka, K. Nogi, M. Fukusumi, Fullerene/A5083 composites fabricated by material flow during friction stir processing, Composites: Part A 38 (2007) 2097-2101 gi , M. Fukusumi , Fullerene/A5083 composites fabricated by material flow during friction stir processing, Composites: Part A 38 (2007) 2097-2101

[7] Sader ,Msc Thesis, University of Technology, Dep. of Production and Metallurgy Eng., Baghdad (2008). 
[8] Essam R. I. Mahmoud, Makoto Takahashi, Toshiya Shibayanagi and Kenji Ikeuchi, Fabrication of Surface-Hybrid-MMCs Layer on Aluminum Plate by Friction Stir Processing and Its Wear Characteristics, Materials Transactions, Vol. 50, No. 7 (2009) pp. 1824 to 1831.

[9] C.J. Lee, J.C. Huang, P.J. Hsieh. Mg based nano-composites fabricated by friction stir processing, Scripta Materialia 54 (2006) 1415-1420.

[10] Osama Sultan Mohamed, Micro-structure and Wear Rate of Al Alloy based composites, Engineering and Technology, 28 (2010), 23. 